\title{
Development of a feature recognition module for tapered and curved base features.
}

\author{
ARIVAZHAGAN, A., MEHTA, N.K. and JAIN, P.K.
}

2008

The final authenticated version is available online at: $\mathrm{https}$ ://doi.org/10.1007/s00170-007-1212-8. This precopyedited version is made available under the Springer terms of reuse for AAMs:

https://www.springer.com/gp/open-access/publication-policies/aam-terms-of-use 


\title{
Development of a feature recognition module for tapered and curved base features
}

\author{
A. Arivazhagan · N. K. Mehta · P. K. Jain \\ Department of Mechanical and Industrial Engineering,Indian Institute of Technology Roorkee, Roorkee 247667, India
}

\begin{abstract}
This paper presents a feature recognition module which uses the B-rep details extracted from the Standard for Exchange of Product (STEP) format to recognize the manufacturing features on a prismatic part. It adopts the syntactic pattern recognition technique to recognize five classes of features considered in this research by matching the standard pattern strings developed for every class of the feature. Using these strings, initially, the types of faces onthe prismatic part are determined and edge loops are constructed. The edge loops describe a feature by the information implicit in the details of the edges, vertices, coordinate points, and directions. Using the edge loops andby checking the presence of similar edge loops on parallel faces and the connectivity of faces between parallel edge loops, the final shape of a feature is identified. The developed methodology identifies interacting, tapering, interacting-tapering, curved base features, and tapering cross-sections. Methodologies are presented here to calculate the full dimensional details of all of the features. A casestudy dealing with complex geometries is presented in the validation of the proposed feature recognizer.
\end{abstract}

Keywords Feature recognition, Syntactic pattern recognition, Tapering and interacting features, Edge loop and face.

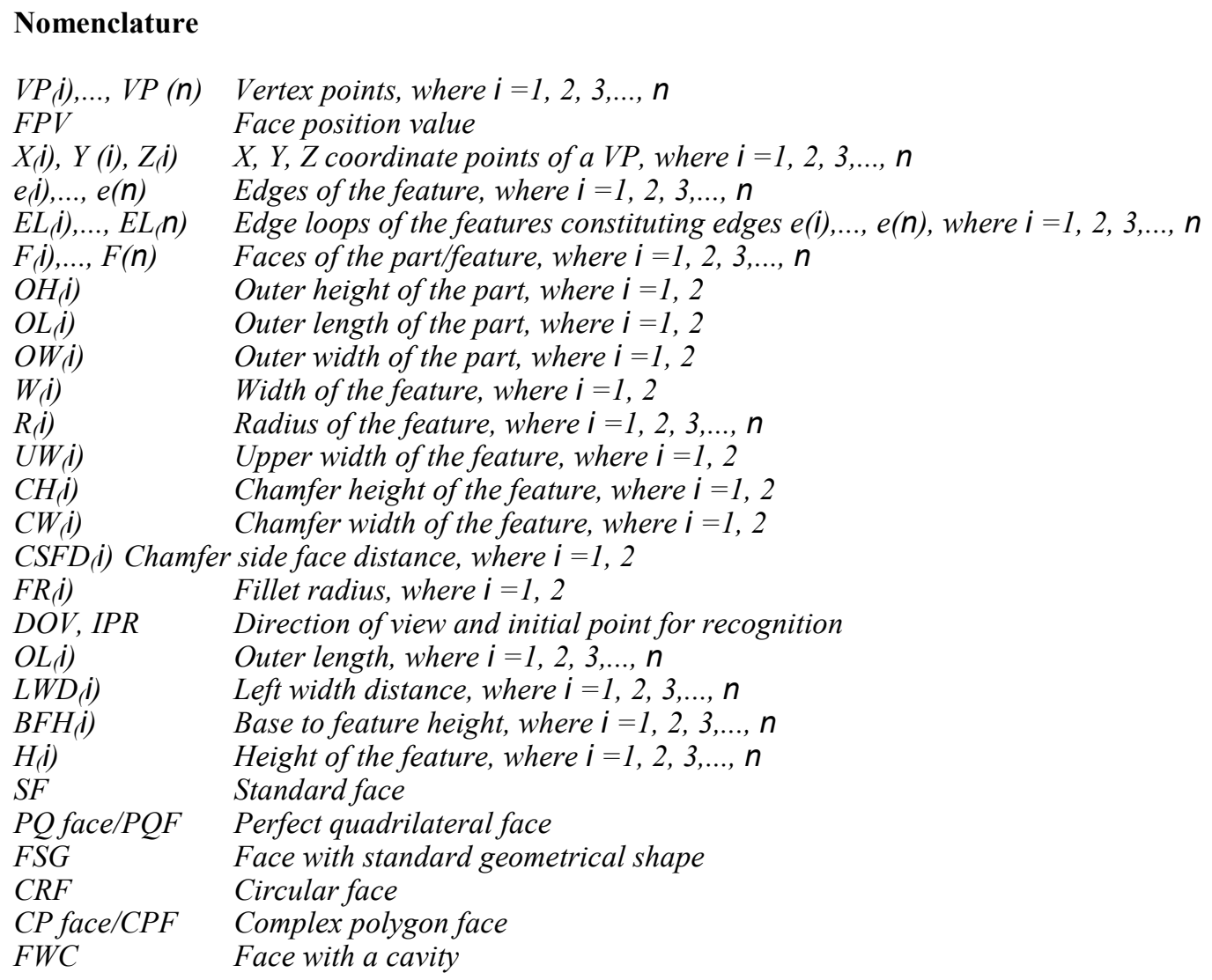




\section{Introduction}

The term "feature" holds different definitions in various fields owing to the nature of its usage. In the design area, itis termed as a design feature and is defined as "an object which contains the details of geometrical and topological relationships to define the edges, vertices and coordinate points with their size, shape and orientation in respective planes." In machine dynamics, it is termed as a functional feature and is defined as "an object which contains the details of a dynamic operation with kinematical relationships showing the movement in a particular axis." In the manufacturing field, it is termed as a manufacturing featureand is defined as "an object which contains the details of removal volume required for a particular machiningoperation." Generally, in computer-aided process planning (CAPP) systems, feature recognition serves as the means oftranslating the design features into manufacturing features by utilizing the details of geometrical and topological parameters from the design to identify the size of the removal volume, tool approach direction, and number of passes required for a machining operation. Most CAPPsystems are developed by following two approaches; variant and generative. The former focuses on developing the process plans by adopting a suitable group technology (GT) coding scheme, whereas the latter uses expert rules toselect appropriate machining methods required to completethe part. In both of the approaches, a part model in neutral format is adopted and feature extraction is carried out by one of several techniques, namely, syntactic pattern recognition, volume decomposition, attributed adjacencygraph, etc., to convert the part design details in B-rep data from the neutral formats into manufacturing features. Most of the CAPP systems developed so far deal with a varietyof straight features of slot class, step class, hole/pocket class, and their interactions with each other on the planes [1-6]. These systems are found lacking in the identificationof complicated features, such as tapering features, features with curved bases, and interacting features of these combinations [1-6]. This research work concentrates on developing a feature recognizer for recognizing complicated features such as tapered cross-sections, curved bases, and their interactions, and is an extension of the work of Hebbal [1] on the rough machining of normal featuresadopting the DXF (drawing exchange) format. In the proposed feature recognizer (Fig. 1), the details of the rough machined part and the final part are extracted from STandard for Exchange of Product (STEP) data [AP203/214] neutral formats after modeling in the SolidWorks software package. The part details from the STEP AP203/ 214 formats extracted by the interfacer (IFST) are inputted to the feature recognizer, which adopts the syntactic patternrecognition technique to recognize the features present in the rough machined part and the final part.

In this research, a feature recognizer has been developedwhich is capable of identifying the combinations of different shapes of features differentiated on the basis of slot, step, pocket/hole, chamfer, and fillet. The proposed feature recognizer is capable of recognizing 28 normal features and nine types of taper. Combinations of the nine types of taper with each of the 28 normal features producesa total of $28 \times 9=252$ tapered features. However, some of these features are irrelevant and, after due analysis, 195 tapered features that are functionally relevant have been identified. The 28 normal features are listed as follows:

- (i) Ordinary through slot, OTSL

- (ii) Ordinary blind slot, OBSL

- (iii) Ordinary through dovetail slot, OTDSL

- (iv) Ordinary through V-slot, OTVSL

- (v) Ordinary blind V-slot, OBVSL

- (vi) Ordinary W-slot, OWSL

- (vii) Ordinary blind W-slot, OBWSL

- (viii) Ordinary through T-slot, OTTSL

- (ix) Ordinary through slot with curved base, OTSLCB

- (x) Ordinary blind slot with curved base, OBSLCB

- (xi) Ordinary through step, OTST

- (xii) Ordinary blind step, OBST

- (xiii) Ordinary step with inclined wall, OSTIWL

- (xiv) Ordinary step with inclined floor, OSTIFL

- (xv) Ordinary step with blending edge, OSTBE

- (xvi) Ordinary step with curved corner, OSTCC

- (xvii) Ordinary rectangular through pocket/hole, ORTPH

- (xviii) Ordinary rectangular blind pocket/hole, ORBPH

- (xix) Ordinary circular through hole/pocket, OCBHP 
- (xx) Ordinary circular blind hole/pocket, OCBHP

- (xxi) Ordinary blind dovetail slot, OBDTSL

- (xxii) Ordinary blind T-slot, OBTSL

- (xxiii) Ordinary blind step with inclined wall, OBSTIWL

- (xxiv) Ordinary blind step with inclined floor, OBSTIFL

- (xxv) Ordinary blind step with blending edge, OBSTBE

- (xxvi) Ordinary blind step with curved corner, OBSTCC

- (xxvii) Through slot with blending edge, TSLBE

- (xxviii) Blind slot with blending edge, BSLBE

Fig. 1 Block diagram of the feature recognition module in finish machining computer aided process planning system (FM-CAPP)

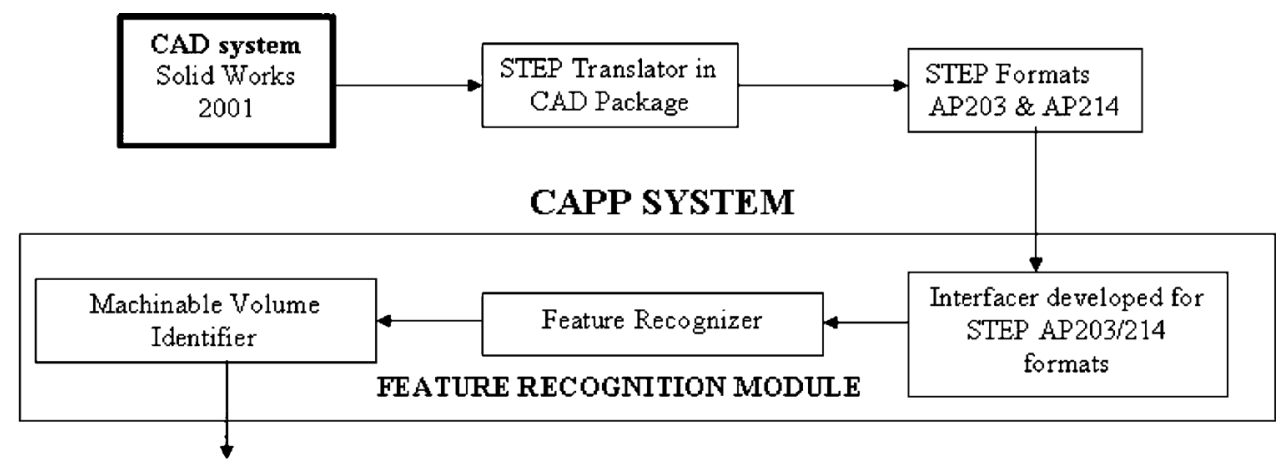

MACHINING PLANNING MODULE

The nine types of taper are as follows:

- (i) Feature having taper at the top face of the part

- (ii) Feature having taper at the base of the part

- (iii) Feature having taper at the base of the part

- (iv) Feature having tapered walls in the part (right wall,left wall, or both)

- (v) Feature having chamfer tapering towards the end

- (vi) Feature having fillet tapering towards the end

- (vii) Feature having taper at the side face of the part (right, left, or both)

- (viii) Feature narrowing at the end (tapering at the baseand at the walls)

- (ix) Feature having most of the above considered combinations (tapering at the top face, bottom face, side face, chamfer, fillet, narrowing at the end)

These features are considered as micro features when their dimensions lie between 1-3 $\mathrm{mm}$.

\section{Literature review}

Recognizing machining features from a CAD model is the first and foremost task in a CAPP system to plan further activities. This section presents the various methodologies developed to identify manufacturing features by using different feature recognition approaches and neutral formatsduring the last two decades. Hebbal [1] developed a featurerecognition system using a syntactic pattern recognitiontechnique named CAPPS_PRINTER. He developed a feature recognizer to recognize primitive depression, protrusion, planar, and inclined features and also certain complex features and a wide range of interacting features. Sandiford and Hinduja [2] developed a feature recognition system to identify features, namely, step, slot, pocket, and protruded features by using volume decomposition technique. Huang and Yip-Hoi [3] proposed a methodology forextracting application-specific features, known as high-level features (such as holes, slots pockets, and notches) byusing feature relationship graphs. Jain and Kumar [4] presented an approach to identify volumetric features (suchas slot in slot, slot 
in step combinations) from three-dimensional wire frame models for prismatic parts. Dereli and Filiz [6] identified normal features (slot, step, through hole) from prismatic parts using the STEP AP203 format. In their approach, they validated the models by means ofEuler's law and used attributed adjacency relationship graphs for identifying the features in the part.

A brief overview of feature recognition techniques has been given by Subrahmanyam and Wozny [7]. They discussed several feature recognition techniques, namely: (i) volume decomposition techniques, such as convex hull, cavity volume; (ii) decomposition by slicing laminae; and recent approaches such as attributed adjacency graph, frame-based feature extraction, hint-based feature recognition, and shape feature object graph. Qiang and Marefat [8]interpreted CAD data for manufacturing applications and pointed out the limitations as well as future directions of research in this area, namely; (i) most of the existing approaches of automatic feature recognition are limited to aparticular application; (ii) the definition of features in CADsystems is application-oriented; (iii) the recognized featuresneed validation for the given application; (iv) standardization is necessary for transferring a model from one system to another system; and (v) data regarding tolerances, surface finish, and functional features have to be effectivelyutilized for feature recognition. Han and Requicha [9] developed a feature recognizer named IfP $^{2}$ using a hint-based reasoning approach to interpret the part in terms of machining features by characterizing them as slot, step, V-groove, etc.

\subsection{Literature on feature recognition techniquesusing vendor-neutral formats}

Abouel Nasr and Kamrani [10] proposed an intelligent feature recognition methodology to develop a feature recognition system suitable for various CAD/CAM systems. They adopted an object-oriented approach and converted the CAD data stored in IGES format into an object-oriented data structure to identify various features (slot, step, and pocket). Ferreira and Vivian [11] presented asystem for recognizing features such as cylinders, cones, and chamfers in cylindrical parts in an Internet-oriented CAD/CAM system. They used an ACIS modeler for designing and converted the SAT format into a VRML format useful for accessing through the Internet. An overview of previous research in the domain of feature recognition using various vendor-neutral standards is given in [12-14]. Sadaiah et al. [15] designed and developed a generative CAPP system for aerospace prismatic components. In their system, API was used from SolidWorks 98 Plus, with VB 6.0 and Oracle 7.3 as a back end tothe CAPP system. Ibrahim and McCormack [16] presented a new method for defining features based on a type of hint-based taxonomy. In their method, they modified the traditional attributed adjacency graph technique andavoided the extraction of sub graphs for the feature identification process.

Chen et al. [17] presented an object-oriented hierarchicalcase representation scheme for automotive panels in a case-based CAPP system. In their approach, they developed twomodels, named extended object model (EOM) and case object model (CAOM), and divided the system into three kinds for solving the problem. They are as follows: (i) the part's information, including general and geometric information; (ii) indexing information used for case retrieval; and (iii) the generation of process plans. Pal et al. [18] presented a hybrid approach for extracting normal and non-interacting 3D features from large CAD databases using a genetic algorithm (GA). They applied a GA to select the best solution and to avoid a large number of insignificant options while dealing with features in the database. They also presented a strategy for machining the interacting features using a spatial reasoning approach [19]. Pal and Kumar [20] presented a hybrid approach for the identification of 3D features from CAD databases. The hybrid approach is partly mathematically iterative and partly basedon heuristic rules. In their publication, details are given for the experimental results, together with the CPU times.

Sakuari [21] decomposed polyhedral objects such aspolygons and polyhedrons into the maximum number of convex cells and generated a global elimination matrix. Further, he identified the delta volume required for theremoval and generated the sequence of operations to machine the part. Zhou et al. [22] presented an approachto integrate CAD and CAPP using commercial systems. They focused on 5-key techniques to integrate CAD/CAPP/CAM, namely; (i) feature parameters and constraints extraction; (ii) feature precedence tree reconstruction; (iii) technical information processing; (iv) automatic process marking; and (v) 3D material stock geometric model generation. Ismail et al. [23] presented a new algorithm to recognize features, called the edge boundary classification technique, for the recognition of conical features, through and blind holes, bosses, and internal undercuts.

\subsection{Literature on feature recognition techniques using STEP protocols}

Another interesting research related to CAPP using theSTEP protocol AP203 has been carried out by Lau et al. [24], who proposed a methodology for integrating CAD data with CAPP. They extracted the features from a STEP AP203 file and generated process plans using the GT approach, using a rule-based decision support system for identifying the features from a STEP file. Gao et al. [25] presented a feature-based CAD/CAM integration system and discussed the difficulties faced during the integration. They focused on the hole-series features that are present in gearbox components. In their system, they developed an approach to convert the design feature model into the machining feature model in order to realize the interest 
of feature-based CAD and CAPP activities. Finally, they converted the whole data set into STEP format (AP224) and tested it with a CAPP system. McCormack and Ibrahim [26] used adjacency-based feature extraction methodology to recognize the features of prismatic parts from the STEP file. An integrated geometric modeling system that supports featurebased modeling and a feature recognizer forextracting machining features have been developed by Lee and Kim [27]. Features similar to that defined in AP224, i.e., depression, protrusion, and transition features, were modeled and rough machining volumes required for 3-axis milling operations were extracted. A system to interlink design and process planning for prismatic parts has been developed by Kang et al. [28] by considering the STEP AP224 format. Fu et al. [29] also proposed an approach for identifying the manufacturing features from IGES, STEP AP214, DXF, and SAT formats. From the analysis of the literature, it is evident that research over thepast two decades has concentrated mainly on recognizing the normal features and their interactions in prismatic parts.For these features, different types of feature recognition techniques and methodologies have been developed forsolving the complications encountered while interlinking product data with the CAPP systems. Further, various neutral formats from CAD systems, namely, DXF, IGES, PDES, and STEP, are used to extract the B-rep details. It isseen that the identification of tapered and curved base features has not been given due attention. It is, therefore, proposed to develop a new approach based on a syntactic pattern recognition technique for identifying the features oftapered cross-sections and curved bases using the STEP standard. New methodologies for identifying taperedfeatures are uniquely developed based on existing concepts. The details of the basic concepts and methodologies developed in this research are presented in the next section.

\section{Basic concepts adopted for feature recognition}

A brief overview of all of the basic concepts adopted for feature recognition in prismatic parts taken from Hebbal [1]is presented below:

1. Additional edges. The entire area of a face is enclosedby a set of edges arranged in the form of a closed geometrical structure. These edges are called the mainedges or, simply, edges. In some cases, apart from themain edges, a face may have another set of edges arranged in the form of a closed structure or a circularedge, representing a cavity on the face. Such edges arereferred to as "additional edges." A schematic representation of main edges and additional edges is shown in Fig. 2a.

2. Edge loop $\left(\mathrm{EL}_{1}, \mathrm{EL}_{2}, \ldots\right)$. The successive edges of a face having the predefined string of a feature is termedas an edge loop. In Fig. 2b, the successive edges $\mathrm{e}_{1}, \mathrm{e}_{2}$, and $\mathrm{e}_{3}$ constituting the string "BID" for the feature blind slot with curved base is termed as an edge loop with notation $\mathrm{EL}_{1}$.

3. Face geometry. Provides the information about the shape of a face, such as rectangular face, polygonal face, etc. In this research, the different types of faces are classified based on the concept of edge loops as:

(a) face having no edge loops, namely, perfect quadrilateral faces, standard geometrical shapes, such as rectangle, square, polygon, etc., and (b) face havingedge loops, namely, perfect quadrilateral face (PQ face/PQF), face with standard geometrical shape (FSG) (other than a rectangle, square, and circle), complex polygon face (CPF), face with a cavity (FWC), and circular face (CRF). An example of a CPF face (with edge loops) is shown in Fig. 2c.

4. Face position value. The constant value in a collectionof coordinate points representing the face is termed asthe face position value. In Fig. $2 d$, the coordinates of $X$ values and $Z$ values present in the $X-Z$ plane of face $F 1$ vary, whereas the $Y$ values remain constant, i.e., 0 . This value of $Y(0)$ is taken as the face positionvalue for a face in that plane. Similarly, the values of $\mathrm{X}$ in the $\mathrm{Y}-\mathrm{Z}$ plane and $\mathrm{Z}$ in the $\mathrm{Z}-\mathrm{Y}$ plane are examples of face position values. These values represent the placement of the face in a particularplane. It may be noted that an inclined plane will havetwo FPVs.

5. Direction of view (DOV). The viewing direction of a face in a particular plane is termed as the direction of view. In this research, the $\mathrm{Y}-\mathrm{Z}, \mathrm{X}-\mathrm{Z}$, and $\mathrm{X}-\mathrm{Y}$ planesare viewed from the right, front, and top, respectively.The DOVs are represented separately in Fig. $2 \mathrm{~d}$.

6. Initial point for recognition (IPR). The initial point from which the recognition starts for a face is known as the initial point of recognition. In this research, the lower left corner is considered as the initial point of recognition. 


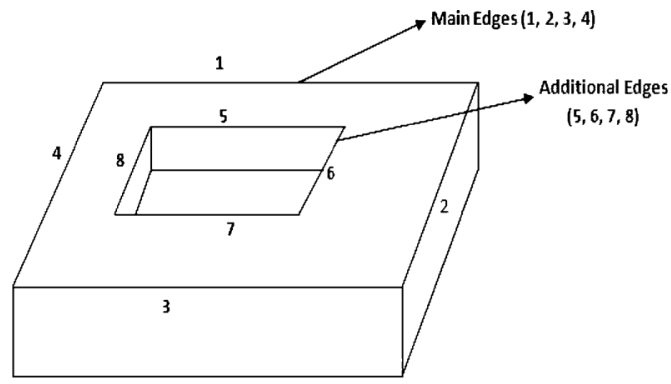

a

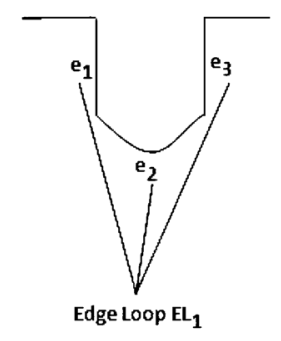

b
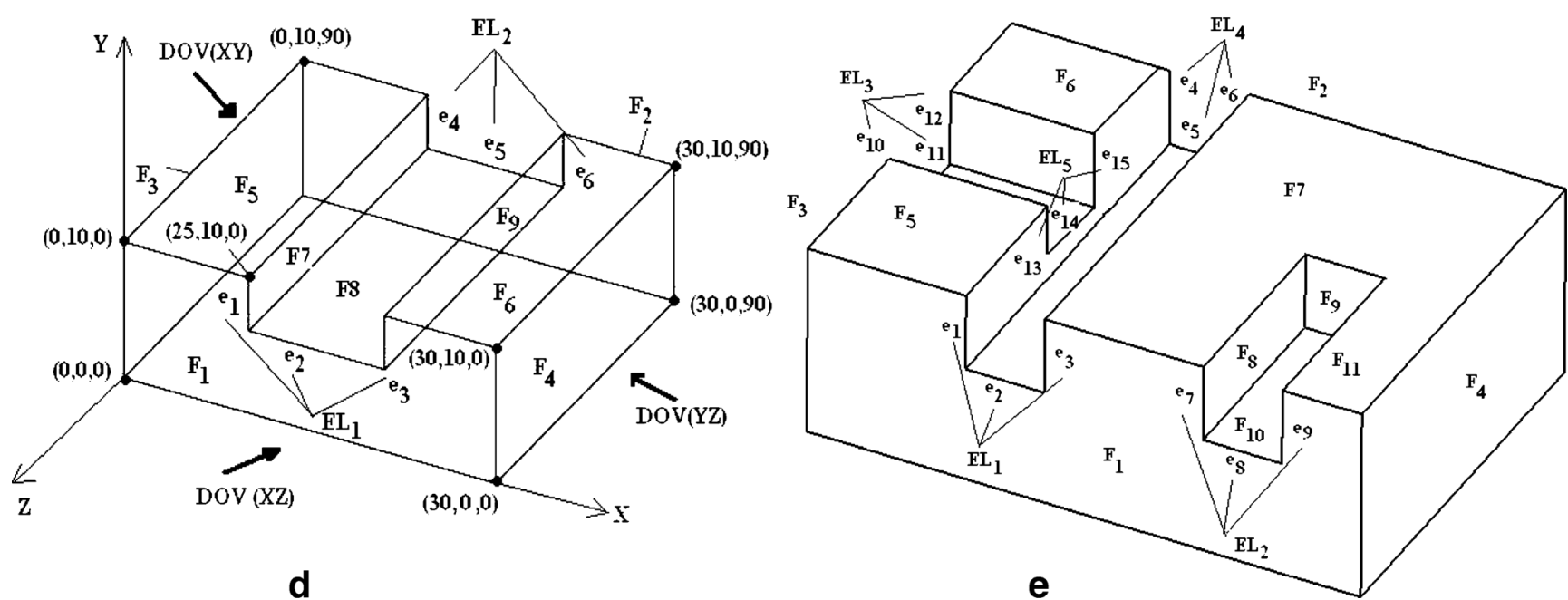

Fig. 2 a Part representing additional and main edges. b Representation of edge loop. c Representation of face geometry. d Example prismatic part to explain the basic concepts-I. e Example prismatic part to explain the basic concepts-II

7. Corresponding edges. The term corresponding edges is used to describe an interrelationship between two edges. For example, in Fig. $2 d$, the edges $\left(\mathrm{e}_{1}, \mathrm{e}_{2}, \mathrm{e}_{3}\right)$ and $\left(\mathrm{e}_{4}, \mathrm{e}_{5}, \mathrm{e}_{6}\right)$ having identical strings can be recognized on parallel faces $\mathrm{F}_{1}$ and $\mathrm{F}_{2}$, respectively, in the $\mathrm{X}-\mathrm{Z}$ plane. For such parallel edge loops, corresponding edges can be defined as follows: an edge $\mathrm{e}_{(i)}\left(\right.$ say $\left._{\mathrm{e}}\right)$ of one edge loop is said to be the corresponding edge for the edge $\mathrm{e}_{(j)}\left(\mathrm{say}, \mathrm{e}_{4}\right)$ of another edge loop if any one of the following conditions is satisfied: (i) the coordinates representingthe plane, i.e., the $\mathrm{X}$ and $\mathrm{Z}$ coordinates for the edges $\mathrm{e}_{(i)}$ and $\mathrm{e}_{(j)}$ are the same; (ii) both $\mathrm{e}_{(i)}$ and $\mathrm{e}_{(j)}$ areconstituents of an edge set representing a face inclinedto the $\mathrm{X}-\mathrm{Z}$ plane (since both edge loops are located inthis plane); (iii) both of the edge loops $\mathrm{EL}_{1}$ and $\mathrm{EL}_{2}$ are of same type, i.e., both are open or closed orcircular edge loops and represented by identical stringsubsets; and (iv) both faces, i.e., $\mathrm{F}_{1}$ and $\mathrm{F}_{2}$ are in the same plane.

8. Common face. Defined as the face that contains two edges of different edge loops present in similar planes. An example of a common face in the part shown in Fig. $2 \mathrm{~d}_{\text {is }} \mathrm{F}_{7}$, which contains two edges of different edges $\mathrm{e}_{1}$ and $\mathrm{e}_{4}$.

9. Linking face. The face which joins two adjoint edge loops in faces present in similar planes. The linking faces in Fig. $2 \mathrm{~d}$ for the feature slot containing edges $\left(\mathrm{e}_{1}, \mathrm{e}_{2}, \mathrm{e}_{3}\right)$ and $\left(\mathrm{e}_{4}, \mathrm{e}_{5}, \mathrm{e}_{6}\right)$ are $\mathrm{F}_{7}, \mathrm{~F}_{8}$, and $\mathrm{F}_{9}$.

10. Parallel edge loops. Two edge loops are considered asparallel if: (i) the coordinate points which constitute the edges shares a common difference; (ii) both of theedge loops lie in the same plane; (iii) the string represented by the edge loop is similar. In the part shown in Fig. $2 \mathrm{e}, \mathrm{EL}_{1}$ on face $\mathrm{F}_{1}$ and $\mathrm{EL}_{4}$ on face $\mathrm{F}_{2}$ are parallel edge loops.

11. Face parallel to an edge loop. A face is considered to be a parallel face to the edge loop if: (i) the face lies inthe same plane as the edge loop; (ii) there is a presence of connecting faces between the edge loops. In Fig. 2e, the face $\mathrm{F}_{9}$ for the blind slot having edge loop $\mathrm{EL}_{2}\left(\mathrm{e}_{7}, \mathrm{e}_{8}, \mathrm{e}_{9}\right)$ is a face parallel to the edge loop.

12. Set of edge loops representing interacting features. Edge loops are considered as a set that represents the interacting features if the edge loop is present in the connecting face of the two parallel edge loops. In Fig. 2e, the edge loop EL $E_{1}$ $\left(\mathrm{e}_{1}, \mathrm{e}_{2}, \mathrm{e}_{3}\right)$ contains a paralleledge loop $\mathrm{EL}_{4}\left(\mathrm{e}_{4}, \mathrm{e}_{5}, \mathrm{e}_{6}\right)$ with $\mathrm{EL}_{3}\left(\mathrm{e}_{10}, \mathrm{e}_{11}, \mathrm{e}_{12}\right)$ and $\mathrm{EL}_{5}\left(\mathrm{e}_{13}, \mathrm{e}_{14}, \mathrm{e}_{15}\right)$, representing an interacting feature. 
Apart from the above concepts, some standard concepts, such as pattern primitives and strings, are well known and can also be obtained from standard sources [30].

\section{Methodology to determine normal and taperedfeatures}

The methodology of determining normal features is described in [8] and the same has been adopted in the present work. The methodology of recognizing tapered features is presented here and is explained through Fig. 3a,b:

Step 1. Projection of point on parallel edge loop. To checkwhether the feature is tapered or straight, the vertex point of an edge is projected from one end of the edge in a perpendicular direction to a certaindistance (in case of blind features) or to a parallel vertex connected by the parallel edge. In Fig. 3a, b, point $\mathrm{p}_{1}$ of edge $\mathrm{e}_{1}$ of edge loop EL $\mathrm{L}_{1}$ is projected to the parallel face $F_{2}$ in a perpendiculardirection to touch the vertex at point $\mathrm{p}_{2}$.

Step 2. Matching of points with the parallel face/edge loops. When the point is projected, it must match either the point in the parallel edge or the parallel face (in case of blind features). To check this, a normal is drawn perpendicularly by connecting the initial point and the projected point. In Fig. 3a,b, the line constructed between points p1 and p3 is schematically represented.

Step 3. Collinearity between points to identify normal or tapered feature. The projected point is checked forcollinearity with the other two points $\mathrm{p}_{1}$ and $\mathrm{p}_{2}$ to determine whether the feature is tapered at the end. This is checked by taking the initial point, projected point, and the parallel point. Three or more points $\mathrm{P}_{1}, \mathrm{P}_{2}, \mathrm{P}_{3}, \ldots$ are said to be collinear if they lie on a single straight line $\mathrm{L}$, i.e., threepoints $\mathrm{P}_{\mathrm{i}}=\left(\mathrm{x}_{\mathrm{i}}, \mathrm{y}_{\mathrm{i}}, \mathrm{z}_{\mathrm{i}}\right)$ for $i=1,2,3$ are collinear if they satisfy the following conditions:

$$
X_{2}-X_{1}: Y_{2}-Y_{1}: Z_{2}-Z_{1}=X_{3}-X_{1}: Y_{3}-Y_{1}: Z_{3}-Z_{1} \text {. }
$$

If the condition is satisfied then the feature is a normal feature; otherwise, the feature is a taperedfeature.

Fig. 3 a Example prismatic part representing a normal feature. $b$ Example prismatic part representing a tapered feature

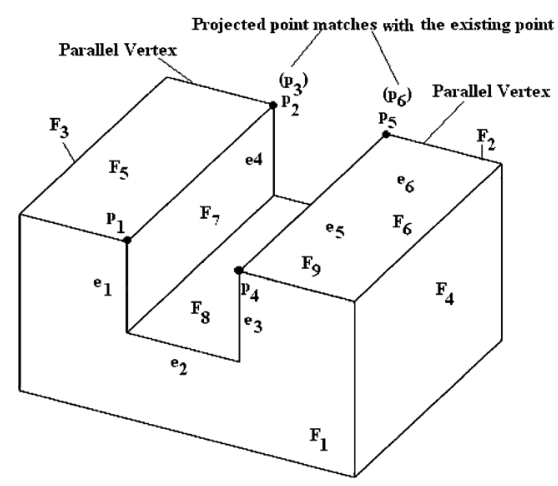

a

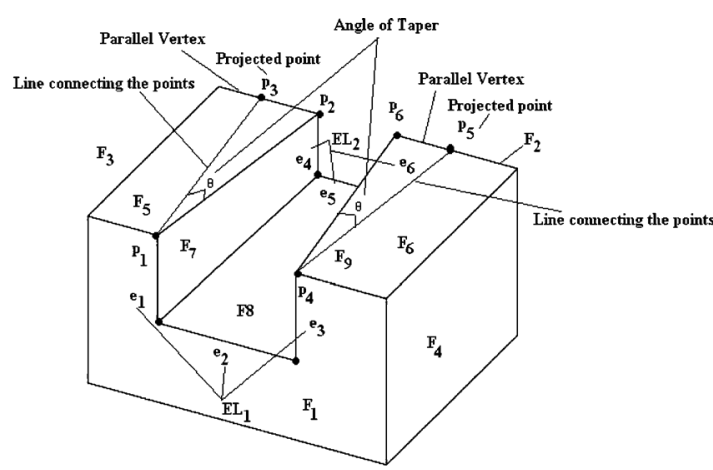

b

\section{Methodologies developed for determining the nature of the taper in the feature}

After determining that the feature is tapered, the type of taper has to be identified. A taper may occur at various areas of the feature and in the part. The taper can vary fromminor to major angles. In order to find the nature of the taper some general procedure has to be followed for every feature. This section explains those procedures for three types of taper. Similarly, procedures have been developed for the remaining six types of tapers listed in Sect. 1.

5.1 Methodology for feature narrowing at the end (taperingat the base and tapering at the walls) 
Here, the feature of slot class type named "ordinary blind dovetail slot narrowing at the end" (OBDSLNE) isconsidered to explain the basic methodology. The schematic representation of the feature is given in Fig. 4a:

Step 1. Calculate the height $\left(\mathrm{H}_{1}\right.$ and $\left.\mathrm{H}_{2}\right)$, width $\left(\mathrm{W}_{1}, \mathrm{~W}_{2}\right)$, upper width $\left(\mathrm{UW}_{1}\right.$ and $\left.\mathrm{UW}_{2}\right)$, and outer length $\left(\mathrm{OL}_{1}\right.$ and $\left.\mathrm{OL}_{2}\right)$ of the part.

Step 2. If $\mathrm{W}_{1}>\mathrm{W}_{2}$ and $\mathrm{UW}_{1}>\mathrm{UW}_{2}$, then the feature isdetermined as a feature that is narrowing towardsthe end if it satisfies the following conditions:

(i) $\mathrm{H}_{1}>\mathrm{H}_{2}$

(ii)Outer Length is equal OL i.e $\mathrm{OL}_{1}=\mathrm{OL}_{2}$ and

(iii) $\mathrm{L}_{1} \& \mathrm{~L}_{2}<\mathrm{OL}_{1} \& \mathrm{OL}_{2}$.

\subsection{Methodology for feature tapering at the top face of the part}

Here, the feature of the slot class "ordinary through slot having taper at the top face of the part" (OTSLTTFC) is shown in Fig. $4 \mathrm{~b}$ as an example to explain the basic methodology:

Step 1. Calculate the height $\left(\mathrm{H}_{1}\right.$ and $\left.\mathrm{H}_{2}\right)$, outer height $\left(\mathrm{OH}_{1}\right.$ and $\left.\mathrm{OH}_{2}\right)$, length $\left(\mathrm{L}_{1}\right.$ and $\left.\mathrm{L}_{2}\right)$, and width $\left(\mathrm{W}_{1}\right.$ and $\left.\mathrm{W}_{2}\right)$ of the feature.

Step 2. If $\mathrm{OH}_{1}<\mathrm{OH}_{2}$, then the feature is determined as a feature with a tapering base only if it satisfies the following conditions:

(i) $\mathrm{W}_{1} \& \mathrm{~W}_{2}$ are equal (ii) $\mathrm{L}_{1}=\mathrm{L}_{2}\left(\right.$ iii) $\mathrm{H}_{1}<\mathrm{H}_{2}$

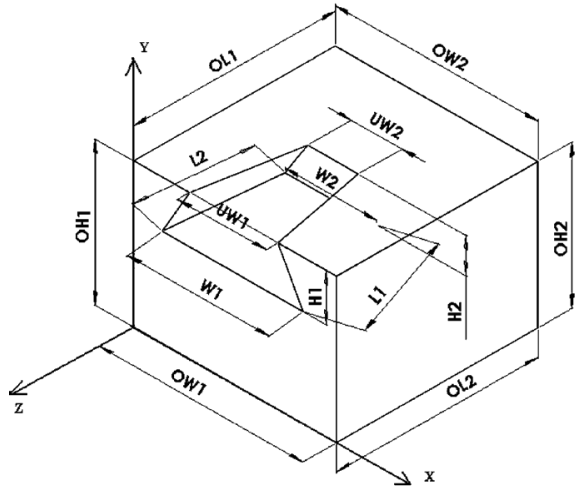

a

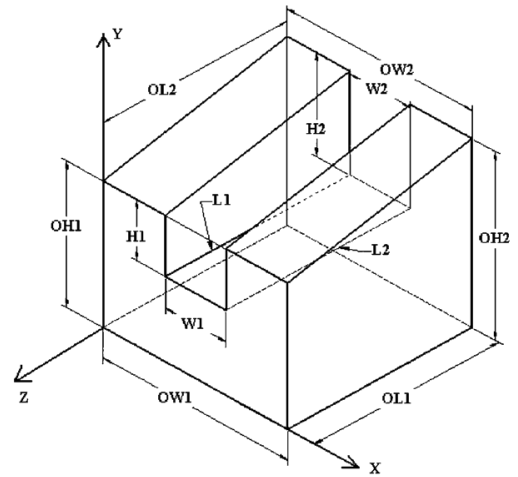

b

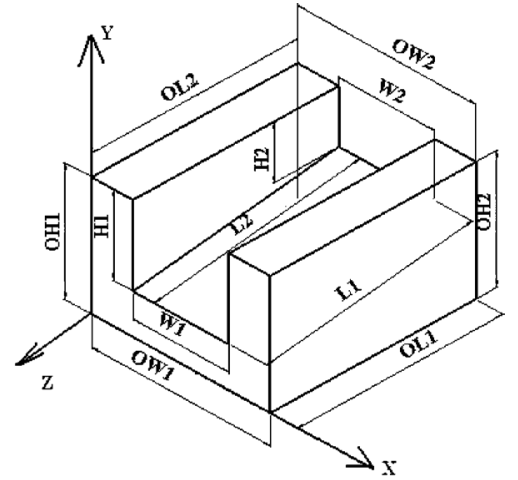

C

Fig. 4 a Ordinary blind dovetail slot narrowing at the end (OBDSLNE). b Ordinary through slot having taper at the top face of the part. c Ordinary through slot having taper at the base of the feature (OTSLTBF)

5.3 Methodology for feature having a taper at the baseof the feature

Here, the feature of slot class "ordinary through slot havingtaper at the base of the feature" (OTSLTBF) is shown in Fig. 4c as an example to explain the basic methodology:

Step 1. Calculate the height $\left(\mathrm{H}_{1}\right.$ and $\left.\mathrm{H}_{2}\right)$, length $\left(\mathrm{L}_{1}\right.$ and $\left.\mathrm{L}_{2}\right)$, width $\left(\mathrm{W}_{1}\right.$ and $\left.\mathrm{W}_{2}\right)$, and outer length $\left(\mathrm{OL}_{1}\right)$ of the feature.

Step 2. If $\mathrm{H}_{1}>\mathrm{H}_{2}$, then the feature is determined as a feature with tapering at the base only if it satisfiesthe following conditions: (i) $\mathrm{W}_{1}=\mathrm{W}_{2}$; (ii) $\mathrm{L}_{2}=\mathrm{L}_{1}$ 


\section{Methodology to calculate taper angle}

After determining the nature of the taper, the final step is tocalculate the taper angle. The taper angle between twoparallel edge loops are calculated by constructing a right- angled triangle in the respective face. In Fig. 3a, a right-angled triangle is constructed by connecting points $\mathrm{p}_{1}, \mathrm{p}_{2}, \mathrm{p}_{3}$ on faces $\mathrm{F}_{5}$ and $\mathrm{F}_{6}$. Then, the angle of the taper iscalculated by applying Pythagoras' theorem.

\section{General steps followed by the feature recognizerto recognize normal and tapered features}

Step 1. The part is viewed from the $\mathrm{X}-\mathrm{Y}, \mathrm{Y}-\mathrm{Z}$, and $\mathrm{Z}-\mathrm{Y}$ directions and faces parallel to these planes are identified.

Step 2. Identify the type of faces on these planes by adopting the standard pattern strings developed for the purpose. Then, group the faces into their categories either as faces with edge loops or faceswithout edge loops.

Step 3. Implement the concept of edge loops and identify the manufacturing features.

Step 4. Match the parallel edge loop in the same plane anddetermine whether the feature is a blind feature orthrough feature or interacting feature with the helpof additional edge loops.

Step 5. Classify the feature according to their sub class as slot/step/pocket/hole/chamfer/fillet and calculatethe necessary dimensions of the feature and part.

Step 6. Identify whether the feature is normal or tapered.

Step 7. If it is tapered, identify the nature of the taper.

Step 8. Finally, calculate the taper angle.

\section{Case study to illustrate the developed featurerecognition methodology}

The prismatic parts shown in Fig. 5a,b are considered to explain the methodology. The prismatic part represents fivefeatures, namely: (i) ordinary blind dovetail slot narrowing at the end (OBDSLNE); (ii) ordinary blind slot having taperat the base of the feature (OBSLTBF); (iii) ordinary throughW-slot narrowing at the end (OTWSLNE); (iv) ordinary through slot with curved base narrowing at the end (OTSLCBNE); and (v) ordinary through rectangular pocket narrowing at the end (OTRPNE). In the prismatic part, all ofthe objects, namely, faces, edges, and angles are represented separately. Before explaining the methodology, these detailsare as follows:

The face $\mathrm{F}_{1}$ contains three edge loops $\mathrm{EL}_{1}\left(\mathrm{e}_{1}, \mathrm{e}_{2}, \mathrm{e}_{3}\right), \mathrm{EL}_{2}\left(\mathrm{e}_{4}, \mathrm{e}_{5}, \mathrm{e}_{6}\right), \mathrm{EL}_{3}\left(\mathrm{e}_{7}, \mathrm{e}_{8}, \mathrm{e}_{9}\right)$ and the parallel face $\mathrm{F}_{2}$ contains one edge loop $\mathrm{EL}_{6}\left(\mathrm{e}_{16}, \mathrm{e}_{17}, \mathrm{e}_{18}\right)$. Similarly, facesF $\mathrm{F}_{3}$ and $\mathrm{F}_{4}$ contain single-edge loops $\mathrm{EL}_{8}\left(\mathrm{e}_{22}, \mathrm{e}_{23}, \mathrm{e}_{24}\right)$ and $\mathrm{EL}_{7}\left(\mathrm{e}_{19}, \mathrm{e}_{20}, \mathrm{e}_{21}\right)$. The top and bottom faces $\mathrm{F}_{5}$ and $\mathrm{F}_{9}$ contain two parallel edge loops, namely, EL $9\left(\mathrm{e}_{25}, \mathrm{e}_{26}, \mathrm{e}_{27}, \mathrm{e}_{28}\right)$ and $\mathrm{EL}_{10}\left(\mathrm{e}_{29}, \mathrm{e}_{30}, \mathrm{e}_{31}\right.$, $\mathrm{e}_{32}$ ). Apart from these edge loops, there are two intermediate edge loops at the intersection of features. They are $\mathrm{EL}_{4}$ $\left(\mathrm{e}_{10}, \mathrm{e}_{11}, \mathrm{e}_{12}\right)$ andEL $\mathrm{L}_{5}\left(\mathrm{e}_{13}, \mathrm{e}_{14}, \mathrm{e}_{15}\right)$. With this information, the next section explains the methodologies as mentioned in the previous Sect. 3-6.

Fig. 5 Prismatic part with interacting features with tapered cross-section and curved base showing the details of the edge loops and faces

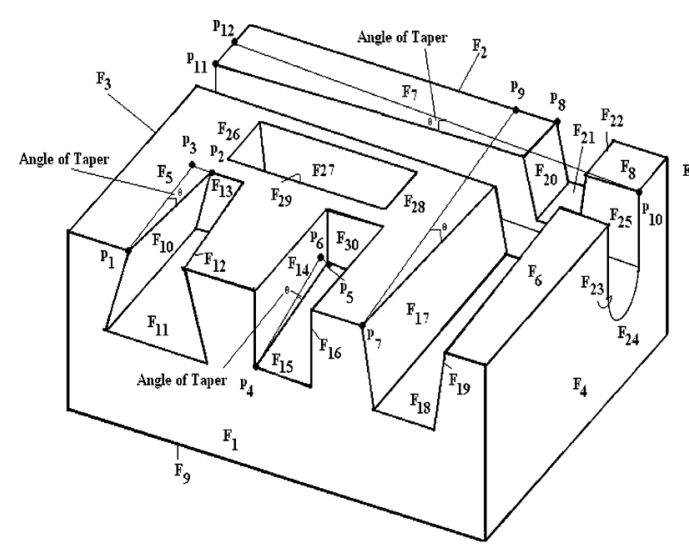

a

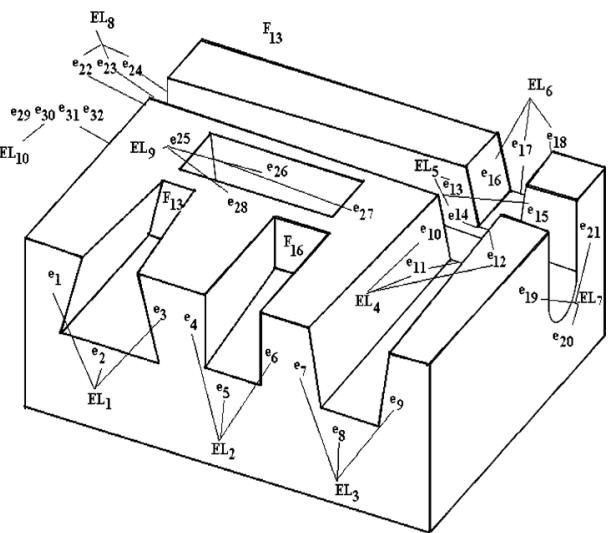

b 


\subsection{Explanation of the feature recognition methodologies}

Step 1. Recognition of face geometry

In this step, initially, each face is viewed in its plane anda suitable string is developed. Then, the type of face is identified by comparing the string with the pre-definedstring stored in the database. In the part shown in Fig. $5 \mathrm{~b}$, the type of face $\mathrm{F}_{1}$ in the $\mathrm{X}-\mathrm{Z}$ plane is identified as a complex polygonal face (CPF) by the string "DAGAHA- BADAFAEABC" and by the presence of three subsets of edge loops, namely, $\mathrm{EL}_{1}, \mathrm{EL}_{2}$, and $\mathrm{EL}_{3}$. Similarly, the details of other faces are presented in Table 2.

Step 2. Identify the manufacturing feature with the edge loops

In this step, the expected manufacturing features aresorted out by identifying the string subsets from the stringsof each face. In the part shown in Fig. 5a,b, the three edge loops in face $F_{1}$ are represented by the string subsets, namely, GAH, BAD, and FAE. By analyzing the strings, they are identified as dovetail slot, ordinary slot, and W- slot, respectively. Similarly, from the string subset $\mathrm{BID}$ in the faces $\mathrm{F}_{3}$ and $\mathrm{F}_{4}$, the feature is identified as a through slot with a curved base. Finally, from faces $\mathrm{F}_{5}$ and $\mathrm{F}_{9}$, the feature is identified as a rectangular pocket by the string $\mathrm{DABC}$.

Step 3. Identify the nature of features (through, blind,interacting)

This step identifies the parallel edge loop (through feature) and the parallel faces (blind feature) for the featurespresent in the part. The procedure adopted for the first threefeatures identified in face $F_{1}$ are explained as follows:

Step 1. Initially for the feature dovetail slot, the presence of a parallel edge loop is checked.

Step 2. The absence of a parallel edge loop and the presence of a parallel face $\mathrm{F}_{13}$ confirms that the feature is blind.

Step 3. Now, a check is performed to ascertain whether a feature is interacting. This is verified by checking the presence of connecting faces of FSG category (face without edge loops), namely, $\mathrm{F}_{10}, \mathrm{~F}_{11}$, and $\mathrm{F}_{12}$.

Step 4. After these checks, the feature is confirmed asa blind W-slot.

The same procedure is followed to identify the nextfeature as a "blind slot" and the feature present in the face $\mathrm{F}_{5}$ as a "through rectangular pocket." As for the W-slot, the first two steps are same, and the remaining steps follow theprocedure mentioned below:

Step 1. Absence of a face of FSG category between $\mathrm{EL}_{3}$ and $\mathrm{EL}_{6}$ provides an initial confirmation that the feature has an interacting feature.

Step 2. Presence of intermediate edge loops, namely, $\mathrm{EL}_{4}$ and $\mathrm{EL}_{5}$, and the presence of FSG faces between edge loops $\mathrm{EL}_{3}$ and $\mathrm{EL}_{4}$ and $\mathrm{EL}_{5}$ andEL 6 provide the secondary confirmation that the feature is interacting.

Step 3. With these confirmations, it is possible to decide that the feature is a through $\mathrm{W}$-slot with an interacting feature.

Next, the features present in faces $F_{3}$ and $F_{4}$ are considered (refer to Table 2). Here, the first two stepsadopted in the dovetail slot and the next three steps adoptedin the W-slot are followed to identify the feature as athrough slot with curved base and with interactions. The only addition is the procedure to find the interacting feature, as explained below:

Step 1. The edge loops $\mathrm{EL}_{4}$ and $\mathrm{EL}_{5}$ present in the feature through $\mathrm{W}$-slot share common edges in the connecting faces $\mathrm{F}_{23}$ and $\mathrm{F}_{25}$ of PQcategory in the feature through slot with curved base.

Step 2. As the two features share common edges on the intersecting points, it is found that thefeatures through slot with curved base and through W-slot are interacting with each other.

Step 3. Classify the feature according to sub class as slot/ step/pocket/hole/chamfer/fillet

After identifying the feature, it is classified according toits main class. The details are presented below:

[1] Blind dovetail slot-slot class

[2] Blind slot-slot class

[3] Through W-slot-slot class

[4] Through slot with curved base-slot class

[5] Through rectangular pocket-pocket class

Step 4. Check whether the feature is normal or tapered atthe end

Now the edge loops are checked to decide whether the feature is normal or tapered. For this, the coordinate points on each edge representing the edge loop are projected perpendicularly to touch the parallel vertex (inthe case of a through feature) or to a certain distance (inthe case of a blind feature) equal to the dimensions of the feature. The details of the projected points for various features in the part are shown in Fig. 5b. The steps are explained below:

1. For the feature "blind dovetail slot," the point $\mathrm{p}_{1}$ onedge $\mathrm{e}_{1}$ is projected perpendicularly to a certain distance 
equal to its length. The projected point is represented as $\mathrm{p}_{3}$. The parallel point that has to be coincided is represented as $\mathrm{p}_{2}$. Now, a line is drawnconnecting these points and checked with the equation given in Sect. 4. As the three points are not collinear, it is confirmed that the feature istapered at one end. Similar checks are performed with the points on the edges $e_{2}$ and $e_{3}$. It also confirms that the feature is also tapered at all of theother points.

2. For the feature "blind slot," the projected points from edge $e_{4}$ lying on face $F_{5}$ satisfy the equation given in Sect. 4 , whereas the second point on face $\mathrm{F}_{1}$ does not satisfy the equation. Similar results are obtained for edge $\mathrm{e}_{6}$ also, whereas for edge $\mathrm{e}_{5}$, the projected points do not conform to the collinearity checks. Hence, from these steps, it is confirmed that the feature is tapered only at the edge $\mathrm{e}_{5}$.

3. Similarly, the features "through W-slot," "through slot with curved base," and "through rectangular pocket" do not satisfy the collinearity check and are confirmed as tapered features. 
Table 1 Methodology adopted to recognize tapered features in the system

\begin{tabular}{|c|c|c|c|}
\hline S.No & Feature Name & Feature Schematic Representation & Methodology \\
\hline 1 & $\begin{array}{l}\text { Ordinary Blind } \\
\text { Slot having } \\
\text { Taper at the } \\
\text { Base of the } \\
\text { Feature } \\
\text { OBSLTBF }\end{array}$ & & $\begin{array}{c}\mathrm{H}_{1}>\mathrm{H}_{2} \\
\mathrm{~L}_{1} \& \mathrm{~L}_{2}<\mathrm{OL}_{1} \& \mathrm{OL}_{2} \\
\text { (i) } \mathrm{OW}_{1}=\mathrm{OW}_{2} \\
\text { (ii) } \mathrm{OL}_{1}=\mathrm{OL}_{2} \\
\text { (iii) } \mathrm{W}_{1}=\mathrm{W}_{2} \\
\text { (iv) } \mathrm{L}_{1}=\mathrm{L}_{2} \\
\text { (v) } \mathrm{OH}_{1}=\mathrm{OH}_{2}\end{array}$ \\
\hline 2 & $\begin{array}{c}\text { Ordinary } \\
\text { Through Step } \\
\text { Having Taper at } \\
\text { the Base of the } \\
\text { Feature } \\
\text { OTSTTBF }\end{array}$ & ㅎㅎㅎ & $\begin{aligned} \mathrm{H}_{1}>\mathrm{H}_{2} & \\
\text { (i) } \mathrm{OW}_{1} & =\mathrm{OW}_{2} \\
\text { (ii) } \mathrm{OH}_{1} & =\mathrm{OH}_{2} \\
\text { (iii) } \mathrm{W}_{1} & =\mathrm{W}_{2} \\
\text { (iv) } \mathrm{OL}_{1} & =\mathrm{OL}_{2} \\
\text { (v) } \mathrm{L}_{1} & =\mathrm{L}_{2}\end{aligned}$ \\
\hline 3 & $\begin{array}{l}\text { Ordinary } \\
\text { Through } \\
\text { Rectangular } \\
\text { Pocket } \\
\text { Narrowing at } \\
\text { the End } \\
\text { OTRPNE }\end{array}$ & & $\begin{array}{c}\mathrm{PW}_{1}=\mathrm{PW}_{2} \\
\mathrm{~L}_{1}=\mathrm{L}_{2} \\
\text { (i) } \mathrm{PW}_{1}>\mathrm{LPW}_{1} \\
\text { (ii) } \mathrm{PW}=>\mathrm{LPW}_{2} \\
\text { (iii) } \mathrm{L}_{1}>\mathrm{LL}_{1} \\
\text { (iv) } \mathrm{OH}_{1}=\mathrm{OH}_{2} \\
\text { (v) } \mathrm{LL}_{2}>\mathrm{LL}_{2} \\
\text { (vi) } \mathrm{OL}_{1}=\mathrm{OL}_{2}\end{array}$ \\
\hline 4 & $\begin{array}{c}\text { Ordinary } \\
\text { Through W Slot } \\
\text { having Taper at } \\
\text { the Top Face of } \\
\text { the Part } \\
\text { OTWSLTTFC }\end{array}$ & & $\begin{array}{c}\mathrm{OH}_{1}<\mathrm{OH}_{2} \\
\mathrm{~W}_{1}=\mathrm{W}_{2} ; \mathrm{UW}_{1}<\mathrm{UW}_{2} \\
\mathrm{~W}_{1}<\mathrm{UW}_{1} ; \mathrm{W}_{2}<\mathrm{UW}_{2} \\
\text { (i) } \mathrm{LWD}_{1}>\mathrm{LWD}_{2} \\
\text { (ii) } \mathrm{OW}_{1}=\mathrm{OW}_{2} \\
\text { (iii) } \mathrm{OL}_{1} \& \mathrm{OL}_{2}=\mathrm{L}_{1} \& \mathrm{~L}_{2}\end{array}$ \\
\hline
\end{tabular}




\begin{tabular}{|c|c|c|c|}
\hline S.No & Feature Name & Feature Schematic Representation & Methodology \\
\hline 5 & $\begin{array}{l}\text { Ordinary } \\
\text { Through Slot } \\
\text { with Curved } \\
\text { Base } \\
\text { Narrowing at } \\
\text { the End } \\
\text { OTSLCBNE }\end{array}$ & & $\begin{aligned} \mathrm{W}_{1} & >\mathrm{W}_{2} \\
\mathrm{H}_{1} & >\mathrm{H}_{2} \\
\mathrm{R}_{1} & >\mathrm{R}_{2} \\
\text { (i) } \mathrm{OH}_{1} & =\mathrm{OH}_{2} \\
\text { (ii) } \mathrm{OL}_{1} & =\mathrm{OL}_{2} \\
\text { (iii) } \mathrm{L}_{1} & =\mathrm{L}_{2} \\
\text { (iv) } \mathrm{OW}_{1} & =\mathrm{OW}_{2}\end{aligned}$ \\
\hline 6 & $\begin{array}{l}\text { Ordinary } \\
\text { Through Step } \\
\text { with Blending } \\
\text { Edge } \\
\text { Narrowing at } \\
\text { the End } \\
\text { OTSBENE }\end{array}$ & & $\begin{aligned} \mathrm{W}_{1} & >\mathrm{W}_{2} \\
\mathrm{H}_{1} & >\mathrm{H}_{2} \\
\mathrm{DW}_{1} & >\mathrm{DW}_{2} \\
\text { (i) } \mathrm{BFH}_{1} & <\mathrm{BFH}_{2} \\
\text { (ii) } \mathrm{OL}_{1} & =\mathrm{OL}_{2} \\
\text { (iii) } \mathrm{OW}_{1} & =\mathrm{OW}_{2} \\
\text { (iv) } \mathrm{OH}_{1} & =\mathrm{OH}_{2} \\
\text { (v) } \mathrm{L}_{1} & =\mathrm{L}_{2}\end{aligned}$ \\
\hline 7 & $\begin{array}{c}\text { Ordinary Blind } \\
\text { Slot Narrowing } \\
\text { at the End } \\
\text { OBSLNE }\end{array}$ & & $\begin{array}{c}\mathrm{W}_{1}>\mathrm{W}_{2} \\
\mathrm{H}_{1}>\mathrm{H}_{2} \\
\mathrm{~L}_{1} \& \mathrm{~L}_{2}<\mathrm{OL}_{1} \& \mathrm{OL}_{2} \\
\text { (i) } \mathrm{OH}_{1}=\mathrm{OH}_{2} \\
\text { (ii) } \mathrm{OL}_{1}=\mathrm{OL}_{2} \\
\text { (iii) } \mathrm{OW}_{1}=\mathrm{OW}_{2} \\
\text { (iv) } \mathrm{L}_{1}=\mathrm{L}_{2}\end{array}$ \\
\hline 8 & $\begin{array}{l}\text { Ordinary Blind } \\
\text { Dovetail Slot } \\
\text { Narrowing at } \\
\text { the End } \\
\text { OBDSLNE }\end{array}$ & ₹ & $\begin{array}{c}\mathrm{W}_{1}>\mathrm{W}_{2} \\
\mathrm{H}_{1}>\mathrm{H}_{2} \\
\mathrm{~W}_{1}>\mathrm{UW}_{1} ; \mathrm{W}_{2}>\mathrm{UW}_{2} \\
\mathrm{~L}_{1} \& \mathrm{~L}_{2}<\mathrm{OL}_{1} \& \mathrm{OL}_{2} \\
\text { (i) } \mathrm{UW}_{1}=\mathrm{UW}_{2} \\
\text { (ii) } \mathrm{OH}_{1}=\mathrm{OH}_{2} \\
\text { (iii) } \mathrm{OL}_{1}=\mathrm{OL}_{2} \\
\text { (iv) } \mathrm{L}_{1}=\mathrm{L}_{2} \\
\text { (v) } \mathrm{OW}_{1}=\mathrm{OW}_{2}\end{array}$ \\
\hline 9 & $\begin{array}{l}\text { Ordinary } \\
\text { Through W } \\
\text { Slot Narrowing } \\
\text { at the End } \\
\text { OTWSLNE }\end{array}$ & & $\begin{array}{c}\mathrm{W}_{1}>\mathrm{W}_{2} \\
\mathrm{H}_{1}>\mathrm{H}_{2} \\
\mathrm{UW}_{1}>\mathrm{UW}_{2} \\
\text { (i) } \mathrm{W}_{1}<\mathrm{UW}_{1} ; \mathrm{W}_{2}<\mathrm{UW}_{2} \\
\text { (ii) } \mathrm{OW}_{1}=\mathrm{OW}_{2} \\
\text { (iii) } \mathrm{OL}_{1}=\mathrm{OL}_{2} \\
\text { (iv) } \mathrm{OH}_{1}=\mathrm{OH}_{2} \\
\text { (v) } \mathrm{LWD}_{1}<\mathrm{LWD}_{2}\end{array}$ \\
\hline
\end{tabular}

Type: Slot, Step and Pocket Class; Dimensional Details: $\mathrm{H}_{1}, \mathrm{H}_{2}$ : Height; $\mathrm{W}_{1}, \mathrm{~W}_{2}$ : Width; $\mathrm{OH}_{1}, \mathrm{OH}_{2}$ : Outer Heights; LWD , LWD $_{2}$ : Left Width Distance; UW $\mathrm{UW}_{1}$ : Upper Width 
Table 2 Output obtained from the feature recognizer for the prismatic part shown in Fig. 5a,b

\begin{tabular}{|c|c|c|c|c|c|c|c|c|}
\hline $\begin{array}{l}\text { S. } \\
\text { no. }\end{array}$ & $\begin{array}{l}\text { List of parallel } \\
\text { edge } \\
\text { loops and faces }\end{array}$ & Details of face geometry & $\begin{array}{l}\text { Details of } \\
\text { strings } \\
\text { representing } \\
\text { the features }\end{array}$ & $\begin{array}{l}\text { Results of } \\
\text { collinearity } \\
\text { check }\end{array}$ & $\begin{array}{l}\text { Methodology suited for the } \\
\text { feature }\end{array}$ & $\begin{array}{l}\text { Tool approach } \\
\text { direction and details of } \\
\text { final feature }(\mathrm{mm})\end{array}$ & Taper angle & $\begin{array}{l}\text { Result of final } \\
\text { feature }\end{array}$ \\
\hline 1 & $\mathrm{e}_{1} ; \mathrm{e}_{2} ; \mathrm{e}_{3} \mathrm{kF}_{13}$ & $\begin{array}{l}\mathrm{F}_{1}, \mathrm{X}-\mathrm{Z} \text { plane, } \\
\text { "DAGAHABADAFAEABC" }\end{array}$ & GAH & $\begin{array}{l}\text { All of the } \\
\text { points are } \\
\text { non-collinear }\end{array}$ & $\begin{array}{l}\mathrm{H}_{1}>\mathrm{H}_{2} ; \mathrm{L}_{1} \text { and } \mathrm{L}_{2}<\mathrm{OL}_{1} \text { and } \\
\mathrm{OL}_{2} ; \text { (i) } \mathrm{OW}_{1}=\mathrm{OW}_{2} ; \text { (ii) } \\
\mathrm{OL}_{1}=\mathrm{OL}_{2} ; \text { (iii) } \mathrm{W}_{1}=\mathrm{W}_{2} ; \\
\text { (iii) } \mathrm{L}_{1}=\mathrm{L}_{2} ; \text { (v) } \mathrm{OH}_{1}=\mathrm{OH}_{2}\end{array}$ & $\begin{array}{l}\mathrm{Y}-\mathrm{Z} \text { direction; } \\
\mathrm{UW}_{1}=32.40 ; \\
\mathrm{W}_{1}=58.52 ; \mathrm{H}_{1}=44.51 ; \\
\mathrm{H}_{2}=31.52 ; \mathrm{W}_{2}=34.65 ; \\
\mathrm{W}_{1}=18.51 ; \mathrm{L}_{1}=82.16 ; \\
\mathrm{L}_{2}=82.16\end{array}$ & $\begin{array}{l}\theta=4.28^{\circ} \\
\text { constant } \\
\text { in all } \\
\text { planes }\end{array}$ & $\begin{array}{l}\text { Ordinary blind slo1 } \\
\text { having a taper at } \\
\text { the base of the } \\
\text { feature } \\
\text { (OBSLTBF) }\end{array}$ \\
\hline 2 & $\mathrm{e}_{4} ; \mathrm{e}_{5} ; \mathrm{e}_{6} \mathrm{kF}_{16}$ & $\begin{array}{l}F_{1}, X-Z \text { plane, } \\
\text { "DAGAHABADAFAEABC" }\end{array}$ & BAD & $\begin{array}{l}\text { Only the points } \\
\text { in the edge } e_{5} \\
\text { are non- } \\
\text { collinear }\end{array}$ & $\begin{array}{l}\mathrm{W}_{1}>\mathrm{W}_{2} ; \mathrm{H}_{1}>\mathrm{H}_{2} ; \mathrm{W}_{1}>\mathrm{UW}_{1} ; \\
\mathrm{W}_{2}>\mathrm{UW}_{2} ; \mathrm{L}_{1} \text { and } \mathrm{L}_{2}<\mathrm{OL}_{1} \\
\text { and } \mathrm{OL}_{2} ; \text { (i) } \mathrm{UW}_{1}=\mathrm{UW}_{2} ; \\
\text { (ii) } \mathrm{OH}_{1}=\mathrm{OH}_{2} ; \text { (iii) } \\
\mathrm{OL}_{1}=\mathrm{OL}_{2} ; \text { (iv) } \mathrm{L}_{1}=\mathrm{L}_{2} ; \text { (v) } \\
\mathrm{OW}_{1}=\mathrm{OW}_{2}\end{array}$ & $\begin{array}{l}\mathrm{Y}-\mathrm{Z} \text { direction; } \\
\mathrm{H}_{1}=39.10 ; \mathrm{W}_{1}=32.93 ; \\
\mathrm{L}_{1}=80.79 ; \mathrm{L}_{2}=80 ; \\
\mathrm{W}_{2}=32.93 ; \mathrm{H}_{2}=27.85\end{array}$ & $\begin{array}{l}\theta=8^{\circ} \text { only } \\
\text { at the base } \\
\text { of the } \\
\text { feature } \\
\text { only in the } \\
X-Z \text { plane }\end{array}$ & $\begin{array}{l}\text { Ordinary through } \\
\text { slot having taper } \\
\text { at the base of the } \\
\text { feature } \\
\text { (OTSLTBF) }\end{array}$ \\
\hline 3 & $\begin{array}{l}\mathrm{e}_{7} ; \mathrm{e}_{8} ; \mathrm{e}_{9} \mathrm{k} \\
\mathrm{e}_{10} ; \mathrm{e}_{11} ; \mathrm{e}_{12}: \mathrm{k} \\
\mathrm{e}_{13} ; \mathrm{e}_{14} ; \mathrm{e}_{15}: \mathrm{k} \\
\mathrm{e}_{16} ; \mathrm{e}_{17} ; \mathrm{e}_{18}:\end{array}$ & $\begin{array}{l}\mathrm{F}_{1}, \mathrm{X}-\mathrm{Z} \text { plane, } \\
\text { "DAGAHABADAFAEABC" }\end{array}$ & FAE & $\begin{array}{l}\text { All of the } \\
\text { points are } \\
\text { non-collinear }\end{array}$ & $\begin{array}{l}\mathrm{W}_{1}>\mathrm{W}_{2} ; \mathrm{H}_{1}>\mathrm{H}_{2} ; \\
\mathrm{UW}_{1}>\mathrm{UW}_{2} ; \text { (i) } \mathrm{W}_{1}<\mathrm{UW}_{1} ; \\
\mathrm{W}_{2}<\mathrm{UW}_{2} \text { (ii) } \mathrm{OW}_{1}=\mathrm{OW}_{2} ; \\
\text { (iii) } \mathrm{OL}_{1}=\mathrm{OL}_{2} ; \text { (iv) } \\
\mathrm{OH}_{1}=\mathrm{OH}_{2} ; \text { (v) } \\
\mathrm{LWD}_{1}<\mathrm{LWD}_{2}\end{array}$ & $\begin{array}{l}\mathrm{Y}-\mathrm{Z} \text { direction; } \\
\mathrm{W}_{1}=34.98 \\
\mathrm{~W}_{2}=21.48 \\
\mathrm{UW}_{1}=48.28 \\
\mathrm{UW}_{2}=33.45 \\
\mathrm{H}_{1}=41.44 ; \mathrm{H}_{2}=28.35 \\
\mathrm{~L}_{1}=200.58 \\
\mathrm{~L}_{2}=200.58\end{array}$ & $\begin{array}{l}\theta=2.08^{\circ} \\
\text { constant } \\
\text { in all } \\
\text { planes }\end{array}$ & $\begin{array}{l}\text { Ordinary through } \\
\text { W-slot narrowing } \\
\text { at the end } \\
\text { (OTWSLNE) }\end{array}$ \\
\hline 4 & $\begin{array}{l}\mathrm{e}_{19} ; \mathrm{e}_{20} ; \mathrm{e}_{21} \mathrm{k} \\
\mathrm{e}_{22} ; \mathrm{e}_{23} ; \mathrm{e}_{24}:\end{array}$ & $\begin{array}{l}\mathrm{F}_{4}, \mathrm{~F}_{3}, \mathrm{Y}-\mathrm{Z} \text { plane, } \\
\text { "DABIDABC" }\end{array}$ & BID & $\begin{array}{l}\text { All of the } \\
\text { points are } \\
\text { non-collinear }\end{array}$ & $\begin{array}{l}\mathrm{W}_{1}>\mathrm{W}_{2} ; \mathrm{H}_{1}>\mathrm{H}_{2} ; \mathrm{R}_{1}>\mathrm{R}_{2} ; \text { (i) } \\
\mathrm{OH}_{1}=\mathrm{OH}_{2} ; \text { (ii) } \mathrm{OL}_{1}=\mathrm{OL}_{2} \\
\text { (iii) } \mathrm{L}_{1}=\mathrm{L}_{2} ; \text { (iv) } \\
\mathrm{OW}_{1}=\mathrm{OW}_{2}\end{array}$ & $\begin{aligned} X-Y & \text { direction; } \\
\mathrm{H}_{1} & =39.10 ; \mathrm{H}_{2}=27.25 ; \\
\mathrm{R}_{1} & =16.36 ; \mathrm{R}_{2}=10.36 ; \\
\mathrm{L}_{1} & =242.66 ; \\
\mathrm{L}_{2} & =242.66\end{aligned}$ & $\begin{array}{l}\theta=1.35^{\circ} \\
\text { constant } \\
\text { in all } \\
\text { planes }\end{array}$ & $\begin{array}{l}\text { Ordinary through } \\
\text { slot with curved } \\
\text { base narrowing at } \\
\text { the end } \\
\text { (OTSLCBNE) }\end{array}$ \\
\hline 5 & $\begin{array}{r}\mathrm{e}_{25} ; \mathrm{e}_{26} ; \mathrm{e}_{27} ; \mathrm{e}_{28} \mathrm{k} \\
\mathrm{e}_{29} ; \mathrm{e}_{30} ; \mathrm{e}_{31} ; \mathrm{e}_{32}:\end{array}$ & $\begin{array}{l}\mathrm{F}_{5}, \mathrm{~F}_{9}, \mathrm{X}-\mathrm{Z} \text { plane, } \\
\text { "DADCDEDGDABC"- } \\
\text { "DABC"; "DABC"-"DABC" }\end{array}$ & $\mathrm{DABC}$ & $\begin{array}{l}\text { All of the } \\
\text { points are } \\
\text { non-collinear }\end{array}$ & $\begin{array}{l}\mathrm{PW}_{1}=\mathrm{PW}_{2} ; \mathrm{L}_{1}=\mathrm{L}_{2} ; \text { (i) } \\
\mathrm{PW}_{1}>\mathrm{LPW}_{1} ; \text { (ii) } \\
\mathrm{PW}=>\mathrm{LPW}_{2} ; \text { (iii) } \mathrm{L}_{1}>\mathrm{LL}_{1} \text {; } \\
\text { (iv) } \mathrm{OH}_{1}=\mathrm{OH}_{2} ; \quad \text { (v) } \\
\mathrm{LL}_{2}>\mathrm{LL}_{2} ; \text { (vi) } \mathrm{OL}_{1}=\mathrm{OL}_{2}\end{array}$ & $\begin{array}{l}\mathrm{Y}-\mathrm{Z} \text { direction; } \\
\mathrm{PW}_{1}=91.72 ; \\
\mathrm{PW}_{2}=91.72 ; \\
\mathrm{L}_{1}=36.05 ; \mathrm{L}_{2}=36.05 ; \\
\mathrm{LL}_{1}=20.03 ; \\
\mathrm{LL}_{2}=20.03 ; \\
\mathrm{LPW}_{1}=20.03 \\
\mathrm{LPW}_{2}=20.03\end{array}$ & $\begin{array}{l}\theta=10.3^{\circ} \\
\text { constant } \\
\text { in all } \\
\text { planes }\end{array}$ & $\begin{array}{l}\text { Ordinary through } \\
\text { rectangular } \\
\text { pocket narrowing } \\
\text { at the end } \\
\text { (OTRPNE) }\end{array}$ \\
\hline
\end{tabular}


Step 6. Identifying the nature of the taper in the feature and the part

After finding that the feature is tapered, the next step is to find out the nature of taper in the feature and the part. For this, the methodologies as presented in Table 1 are usedand the following features are finally identified:

1. Ordinary blind dovetail slot narrowing at the end (OBDSLNE)

2. Ordinary blind slot having taper at the base of the feature (OBSLTBF)

3. Ordinary through $\mathrm{W}$-slot narrowing at the end (OTWSLNE)

4. Ordinary through slot with curved base narrowing at the end (OTSLCBNE)

5. Ordinary through rectangular pocket narrowing at the end (OTRPNE)

Step 7. Calculate the angle of the taper in the feature

At this stage, the taper angle is calculated by constructing a right-angled triangle by connecting the points (as shown in Fig. 5b) in the appropriate faces. Then, using Pythagoras' theorem, the taper angle is calculated and the final dimension of the whole feature is presented. The complete details of all of the above steps and their details are presented in Table 2.

\section{Conclusion}

In the present the work, a feature recognizer was developedto recognize complicated prismatic parts containing interacting, tapering, and curved base features. The developed methodology is coded using the $\mathrm{C}$ and $\mathrm{C}++$ languagesrunning in a $\mathrm{VC}++$ compiler. The feature recognizer considers 28 normal features for nine combinations of taper, as described in Sect. 4 . These combinations were tested on a Pentium IV $2.4 \mathrm{GHz}$ PC for its capability of handling combinations of more than one feature. The feature recognizer took a minimum amount of time to recognize the features and to generate the output. The output contains the tool approach direction, details of edge loops, and the dimensions of features with the taper angle as given in Table 2. This output provides an easy interpretation for the next module, the machinable volume identifier, to calculate the finish cut machinable volumes. The feature recognizer can be easily upgraded in the future to recognize features having Bezier, B-spline, and polygon surfaces.

\section{References}

1. Hebbal S (2004) Computer aided process planning for prismatic parts. PhD thesis, IIT Roorkee, India

2. Sandiford D, Hinduja S (2001) Construction of feature volumes using intersection of adjacent surfaces. Comput Aided Design 33:455-473

3. Huang Z, Yip-Hoi D (2002) High-level feature recognition using feature relationship graphs. Comput Aided Design 34:561-582

4. Jain PK, Kumar S (1998) Automatic feature extraction in PRIZCAPP. Int J Comput Int Manufact 11(6):500-512

5. Jain PK (1999) Extraction of compound volumetric features froma three-dimensional wire frame model. Proc Inst Mech Eng B 213:597-613

6. Dereli T, Filiz H (2002) A note on the use of STEP for interfacingdesign to process planning. Comput Aided Design 34:1075-1085

7. Subrahmanyam, Wozny M (1995) An overview of automaticfeature recognition techniques for computer-aided process planning. Comput Ind 26:1-21

8. Qiang J, Marefat MM (1997) Machine interpretation of CAD datafor manufacturing applications. ACM Comp Surv 24(3):264-311

9. Han JH, Requicha AAG (1997) Integration of feature based designand feature recognition. Comput Aided Design 29(5):393-403

10. Abouel Nasr ES, Kamrani AK (2006) A new methodology for extracting manufacturing features from CAD system. Comput IndEng 51:389415

11. Ferreira JCE, Vivian D (2006) Feature recognition in axisymmetrical parts modeled by solids in an Internet-oriented CAD/CAM system. J Mater Process Technol 179:260-267

12. Gibson P, Ismail HS, Sabin MA (1999) Optimisation approaches in feature recognition. Int J Machine Tool Manufact 39:805-821

13. Liu S-C, Gonzalez M, Chen J-G (1996) Development of an automatic part feature extraction and classification system taking CAD data as input. Comput Ind 29:137-150

14. Wong TN, Wong KW (1995) A feature-based design system for computer-aided process planning. J Mater Process Technol 52:122-132

15. Sadaiah M, Yadav DR, Mohanram PV, Radhakrishnan P (2002) Agenerative computer-aided process planning system for prismatic components. Int J Adv Manuf Technol 20:709-719

16. Ibrahim RN, McCormack AD (2005) Robustness and generality issues of feature recognition for CNC machining. Int J Adv ManufTechnol 25:705-713

17. Chen G, Chen J, Zhao Z, Ruan XY (2005) An object-oriented hierarchical case representation of automotive panels in a computer-aided process planning system. Int J Adv Manuf Technol 26:1323-1330

18. Pal P, Tigga AM, Kumar A (2004) Feature extraction from large CAD databases using genetic algorithm. Comput Aided Design 37:545-558

19. Pal P, Tigga AM, Kumar A (2005) A strategy for machining interacting features using spatial reasoning. Int J Machine Tool Manufact 45:269278 
20. Pal P, Kumar A (2002) A hybrid approach for identification of 3D features from CAD database for manufacturing support. Int J Machine Tool Manufact 42:221-228

21. Sakurai H (1995) Volume decomposition and feature recognition.Part 1: polyhedral objects. Comput Aided Design 27(11):833-843

22. Zhou X, Qiu Y, Hua G, Wang H, Ruan X (2007) A feasible approach to the integration of CAD and CAPP. Comput Aided Design 39:324338

23. Ismail N, Abu Bakar N, Juri AH (2005) Recognition of cylindricaland conical features using edge boundary classification. Int JMachine Tool Manufact 45:649-655

24. Lau HCW, Lee CKM, Jiang B, Hui IK, Pun KF (2004) Development of a computer-integrated system to support CADto CAPP. Int J Adv Manuf Technol 26:1032-1042

25. Go J, Zheng DT, Gindy N (2004) Extraction of machining featuresfor CAD/CAM integration. Int J Adv Manuf Technol 24:573-581

26. McCormack AD, Ibrahim RN (2002) Process planning using adjacency-based feature extraction. Int J Adv Manuf Technol20:817-823

27. Lee JY, Kim K (1998) A feature-based approach to extracting machining features. Comput Aided Design 13(30):1019-1035

28. Kang M, Han J, Moon JG (2003) An approach for interlinking design and process planning. J Mater Process Technol 39:589- 595

29. Fu MW, Ong SK, Lu WF, Lee IBH, Nee AYC (2003) An approach to identify design and manufacturing features from a data exchanged part model. Comput Aided Design 35:979- 993

30. Fu KS (1982) Syntactic pattern recognition and applications. Prentice-Hall, Englewood Cliffs, New Jersey 
